\title{
Chemical composition and antimicrobial activity of the essential oil of wild Thymus vulgaris grown in South Jordan
}

\author{
Jehad Al-Shuneigat ${ }^{1}$, Sameeh Al-Sarayreh ${ }^{1}$, Yousif Al-Saraira ${ }^{1}$, Mahmoud Al- \\ Qudah $^{2}$, Ibrahim Al-Tarawneh ${ }^{3}$, Said Al-Dalaen ${ }^{1}$ \\ ${ }^{1}$ Faculty of Medicine, Mutah University, Mutah, Jordan \\ ${ }^{2}$ Faculty of Science, Department of Chemistry Yarmouk University, Irbid, Jordan \\ ${ }^{3}$ Faculty of Science, Department of Chemistry, Albalqa' Applied university, Albalqa, Al-Salt, Jordan
}

\begin{abstract}
There is a high variability in chemical composition of essential oil from Thymus vulgaris grown in different countries and different localities in the same country. Only three reports were published on the essential oil composition of Thymus vulgaris grown in Jordan and non of them reported from South Jordan. The current study aims to determine the essential oil composition of Thymus vulgaris grown wild in South Jordan and to test their activity against clinical isolate antibiotics resistant bacteria. The composition of the essential oil from Thymus vulgaris was determined using GC-MS while the screening for essential oil activity was carried out using disc diffusion method. The results of GC-MS produced forty-eight components of the oil representing more than 97\% of the oil contents, monoterpenes being most abundant (about $85 \%$ ) with thymol (37.05\%), cisdihydrocarvone (9.34\%), carvacrol (8.45\%), hydroxy-3-(3-methyl-2-butenyl)-3-cyclopenten-1-one (8.41\%), pcymene $(5.73 \%)$, cis-sabinene $(4.42 \%), z$-isoeugenol $(3.342 \%)$, and aromadendrene $(3.42 \%)$ as major constituents.

The essential oil from Thymus vulgaris was found to be active against all the tested bacteria except in Pseudomonas aeruginosa. The high concentrations of thymol and carvacrol may account for its high activity against resistant bacteria.
\end{abstract}

Keywords: GC-MS, resistant bacteria, thyme, thymol, carvacrol.

\section{Introduction}

Essential oils are composed of volatile aromatic compounds with strong odor produced by plants as secondary metabolites. They are usually obtained by steam distillation [1]. The use of essential oils in medicines, perfumes, cosmetics and food preservatives is as old as civilization [2]. Different classes of compounds that may be present in essential oils include 1- Terpenes which include: monoterpene and sesquiterpenes, 2-Oxygenated compounds including phenols, alcohols, aldehydes and ketones,esters.

The chemistry of essential oils is influenced by the local geography and weather conditions [3], as well as the season and time of day when the plants are harvested and how they are processed, packaged and stored. A plant such as Thymus vulgaris L (Lamiaceae) (thyme) grown in one area might produce an essential oil with a different chemistry than thyme grown in another location. Thyme is an aromatic plant commonly used in the Mediterranean countries including Jordan as a herbal tea, flavoring agent and spice and a medicinal plant [4]. Extracts from thyme have been used in traditional medicine for the treatment of several respiratory diseases like asthma and bronchitis [5]. Thymus species have been shown to have strong antibacterial, antifungal, antiviral, antiparasitic, spasmolytic and antioxidant activities [4].

In recent decades, the incidence of hospital-acquired infections with antibiotic-resistant bacteria has increased remarkably. Notable amongst these infections is methicillin-resistant staphylococcus aureus (MRSA) $[6,7]$. Antibiotic resistance organisms are an evolving problem requiring new strategies to combat infection due to these strains. A growing trend is "return to nature" [8]. There is mounting evidence in support of the use of plant-derived essential oils against pathogenic microorganisms $[9,10]$. Both clinical and in vitro studies have demonstrated the potent bactericidal properties of some essential oils including efficacy against antibioticresistant strains such as MRSA [11].

The aim of the present work was to determine the essential oil composition of Thymus vulgaris L. type grown wild in Jordan and to test their activity against clinical isolate antibiotics resistant bacteria.

\section{Materials And Methods}

\subsection{Collection and authentication of plants}

Fresh amount of the Thymus valgaris was collected from Mutah, South Jordan, during flowering period and vegetative phase. The plant materials were taxonomically identified and authenticated by the Botanical Survey of Yarmouk University. 


\subsection{Isolation of essential oil}

Aerial parts (100 g) of Thymus valgaris were finely chopped and subjected to hydrodistillation for $4 \mathrm{~h}$ using a Clevenger-type apparatus, yielding 1.2\%, pale yellowish oil. Subsequently, oil was dried over anhydrous sodium sulfate and immediately stored in GC-grade hexane at $4^{\circ} \mathrm{C}$ until the analysis by gas chromatography/mass spectrometry (GC/MS) were carried out.

\subsection{Essential oil composition}

GC-FID analysis: The oils were analyzed in an Agilent (Palo Alto, USA) $6890 \mathrm{~N}$ gas chromatograph fitted with a $5 \%$ phenyl- $-95 \%$ methylsilicone (HP5, $30 \mathrm{~m} \times 0.25 \mathrm{~mm} \times 0.25 \mu \mathrm{m})$ fused silica capillary column. The oven temperature was programmed to elevate from $60^{\circ} \mathrm{C}$ to $240^{\circ} \mathrm{C}$ at $3^{\circ} \mathrm{C} / \mathrm{min}$, and hydrogen was used as carrier gas $(1.4 \mathrm{~mL} / \mathrm{min}) ; 1.0 \mu \mathrm{L}$ of a $1 \%$ solution of the oils in hexane was injected, in split mode (1:30). The injector was kept at $250^{\circ} \mathrm{C}$ and the flame ionization detector (FID) was kept at $280^{\circ} \mathrm{C}$. Concentrations (\% contents) of oil ingredients for Thymus valgaris were determined using their relative area percentages obtained from GC chromatogram, assuming a unity response by all components.

GC-MS analysis: Chemical analysis of the essential oils was carried out using gas chromatography-mass spectrometry (Agilent (Palo Alto, USA) 6890N gas chromatograph). The chromatographic conditions were as follows: column oven program, $60^{\circ} \mathrm{C}\left(1 \mathrm{~min}\right.$, isothermal) to $246^{\circ} \mathrm{C}(3 \mathrm{~min}$, isothermal $)$ at $3^{\circ} \mathrm{C} / \mathrm{min}$, the injector and detector temperatures were $250^{\circ} \mathrm{C}$ and $300^{\circ} \mathrm{C}$, respectively. Helium was the carrier gas (flow rate 0.90 $\mathrm{ml} / \mathrm{min})$ and the ionization voltage was maintained at $70 \mathrm{eV}$. A HP-5 MS capillary column $(30 \mathrm{~m} \times 0.25 \mathrm{~mm}$ i.d., $0.25 \mu \mathrm{m}$ film thicknesses) was used. A hydrocarbon mixture of alkanes $\left(\mathrm{C}_{8}-\mathrm{C}_{20}\right)$ was analyzed separately by GC-MS under same chromatographic conditions using the same HP-5 column. Kovats Retention Indexes (KRIs) were calculated by injection of a series of $n$-alkanes $\left(\mathrm{C}_{8}-\mathrm{C}_{20}\right)$ in the same column and conditions as above for gas chromatography analyses.

Identification of the oil components were based on computer search using the library of mass spectral data and by comparison of their calculated Kovats retention index (KRI) with those of the available authentic standards and literature data.

\subsection{Maintenance and preparation of cultures}

Eight clinical isolates antibiotics resistant bacteria were used in this study. Four strains of Gram positive bacteria: Methicillin-resistant Staphylococcus aureus (MRSA), Methicillin-sensitive Staphylococcus aureus (MSSA), Staphylococcus epidermidis, Streptococcus pyogenes, and four strains of Gram negative bacteria: Escherichia coli, Klebsiella pneumonia, Proteus mirabilis, Pseudomonas aeruginosa, were studied. Isolates were purified on specific nutrient agar plates and characterized by the use of standard microbiological and biochemical methods like Gram stain, catalase test, coagulase test and an API system (bioMerieux, France).

The bacteria were incubated at $37^{\circ} \mathrm{C}$ for $24 \mathrm{~h}$ by inoculation into broth. Inoculums $(1 \mathrm{~mL})$ per plate containing $10^{6}$ bacterial cell $/ \mathrm{ml}$ were spread on Mueller Hinton agar (Oxoid, Hampshire, England).

\subsection{Disc diffusion assay}

The antibacterial activity of the thyme essential oil was determined by the disc diffusion method according to the National Committee for Clinical Laboratory Standards. Sterile paper discs of $6 \mathrm{~mm}$ in diameter were impregnated with $5 \mu \mathrm{L}$ essential oil and deposited on the agar surface. Petri dishes were placed at $4{ }^{\circ} \mathrm{C}$ for 2 $\mathrm{h}$ to facilitate the dissemination of extract on the culture medium, and then incubated at $37^{\circ} \mathrm{C}$ for $24 \mathrm{~h}$. Negative water control and positive antibiotic disc control were used for each sample. At the end of the period, inhibition zones formed on the medium are evaluated in $\mathrm{mm}$. Studies were performed in triplicate.

\subsection{Chemical composition of the essential oil}

\section{Results and Discussion}

The freshly isolated Thymus essential oil was a yellow liquid with yield $1.2 \%$. The identified components of the essential oils, their percentages and retention indices are listed in Table 1.

The components of essential oil were divided into five classes: hydrocarbon monoterpene, oxygenated monoterpenes, hydrocarbon sesquiterpene, oxygenated sesquiterpenes and diterpene (Table I).

Based on GC and GC-MS analysis of the essential oil of thyme, 48 components were identified representing $97.59 \%$ of the total detected constituents. The major constituents of the oil were thymol $(37.05 \%)$, cis-dihydrocarvone $(9.34 \%)$, carvacrol $(8.45 \%)$, hydroxy-3-(3-methyl-2-butenyl)-3-cyclopenten-1-one $(8.41 \%)$, p-cymene $(5.73 \%)$, cis-sabinene (4.42\%), z-isoeugenol (3.342\%), aromadendrene $(3.42 \%)$ as major constitutes. The results shows that the concentrations of thymol and carvacrol is high and higher than reported by other researchers [12-15]. 
Table 1: Constituents (\%) of the essential oil of Thymus valgaris

\begin{tabular}{|c|c|c|}
\hline KRI & Compound & $\% \mathrm{~A}$ \\
\hline 864 & 2E-Hexenal & 0.55 \\
\hline 873 & E-2-Hexen-1-ol & 0.12 \\
\hline 904 & 2,5-Dimethyltetrahydrofuran & 0.12 \\
\hline 931 & $\alpha$-Thujene & 0.77 \\
\hline 940 & $\alpha$-Pinene & 0.52 \\
\hline 958 & Camphene & 0.18 \\
\hline 981 & Sabinene & 0.11 \\
\hline 990 & trans-Isolimonene & 0.36 \\
\hline 999 & delta-2-Carene & 1.51 \\
\hline 1011 & 3-Octanol & 0.52 \\
\hline 1018 & p-Menth-1(7),8-dine & 0.24 \\
\hline 1021 & $\alpha$-Terpinene & 1.72 \\
\hline 1026 & p-Cymene & 5.73 \\
\hline 1028 & Limonene & 0.73 \\
\hline 1031 & 1,8-Cineole & 0.41 \\
\hline 1037 & beta-(Z)-Ocimene & 0.10 \\
\hline 1072 & cis-Sabinene & 4.42 \\
\hline 1073 & para-Mentha-3,8-diene & 0.14 \\
\hline 1085 & para-Mentha-2,4(8)-diene & 0.10 \\
\hline 1097 & Terpinolene & 0.16 \\
\hline 1105 & 2,5-Dimethylstyrene & 0.10 \\
\hline 1111 & $\beta$-Linalool & 0.10 \\
\hline 1118 & $\beta$-Thujone & 0.25 \\
\hline 1190 & cis-Dihydrocarvone & 9.34 \\
\hline 1258 & Carvenone & 0.96 \\
\hline 1271 & cis-Carvone oxide & 1.54 \\
\hline 1295 & Thymol & 37.05 \\
\hline 1304 & Carvacrol & 8.45 \\
\hline 1352 & Eugenol & 0.20 \\
\hline 1379 & 2-Ethyl-5-propylphenol & 0.30 \\
\hline 1380 & Carvacrol acetate & 0.10 \\
\hline 1399 & z-Isoeugenol & 3.42 \\
\hline 1402 & 2-Methyl-5-(1-methylethyl)- acetate Phenol & 0.14 \\
\hline 1412 & Hydroxy-3-(3-methyl-2-butenyl)-3-Cyclopenten-1-one & 8.41 \\
\hline 1422 & $\beta$-Caryophyllene & 0.10 \\
\hline 1436 & Cinerolon & 0.65 \\
\hline 1444 & Aromadendrene & 3.42 \\
\hline 1476 & $\gamma$-Muurolene & 0.32 \\
\hline 1510 & $\gamma$-Cadinene & 0.30 \\
\hline 1520 & 7-epi- $\alpha$-Selinene & 2.21 \\
\hline 1580 & Spathulenol & 0.50 \\
\hline 1590 & Caryophyllene oxide & 0.59 \\
\hline 1592 & Globulol & 0.13 \\
\hline 1610 & 5-epi-7-epi- $\alpha$-Eudesmol & 0.10 \\
\hline 1631 & $\beta$-Cedrene epoxide & 0.11 \\
\hline 1654 & Cedr-8(15)-en-9-alpha-ol & 0.12 \\
\hline 1668 & Valerianol & 0.14 \\
\hline \multirow[t]{8}{*}{1963} & Isophyllocladene & 1.16 \\
\hline & Hydrocarbon monoterpenes & 12.23 \\
\hline & Oxygenated monoterpenes & 72.74 \\
\hline & Hydrocarbon sesquiterpenes & 6.35 \\
\hline & Oxygenated sesquiterpenes & 2.33 \\
\hline & diterpene & 1.16 \\
\hline & Miscellaneous & 2.78 \\
\hline & Total & 97.59 \\
\hline
\end{tabular}

\subsection{Antimicrobial activity}

The results in Table 2 show that Gram-positive bacteria were more sensitive to Thymus vulgaris essential oil than Gram negative bacteria. All tested Gram positive bacteria were sensitive while in Gram negative bacteria E.coli and Proteus mirabilis were sensitive while Klebsiella pneumoniae showed a moderate sensitivity and pseudomonas aeruginosa was resistant. The high content of Thymus vulgaris essential oil with thymol and carvacol may account for its high antibacterial activity.

Table 2. Antibacterial activity of thyme essential oil

\begin{tabular}{llll}
\hline Name of Bacteria used & $\begin{array}{l}\text { Zone of inhibition of } \\
\text { essential oil in mm }\end{array}$ & $\begin{array}{l}\text { Thyme } \\
\text { Antibiotic used } \\
\text { Zone of inhibition } \\
\text { in mm }\end{array}$ & \\
\hline MRSA & 24 & Vancomycin & $19 \mathrm{~mm}$ \\
MSSA & 24 & Vancomycin & $18 \mathrm{~mm}$ \\
S.epid & 26 & Vancomycin & $21 \mathrm{~mm}$ \\
\hline
\end{tabular}




\begin{tabular}{llll}
\hline Strep. pyog & 26 & Clindamycin & $26 \mathrm{~mm}$ \\
E.Coli & 26 & Chloramphenicol & $28 \mathrm{~mm}$ \\
Klebsla. pneu & 12 & Chloramphenicol & $23 \mathrm{~mm}$ \\
Pseudo. aeru & 2 & Ceftazidime & $25 \mathrm{~mm}$ \\
Proteus mirabilis & 23 & Ampicillin & $14 \mathrm{~mm}$ \\
\hline
\end{tabular}
of triplicate

Each test was assayed in triplicate and the values for zone of growth inhibition are presented as means

The fight against bacterial resistance continues to be a major health concerns worldwide. Specifically MRSA has become a serious public health concern. It attracted the attention of the medical research community for urgent need to develop new drugs to treat bacterial infections. Thyme essential oil may provide a solution to overcome the resistant showed by MRSA.

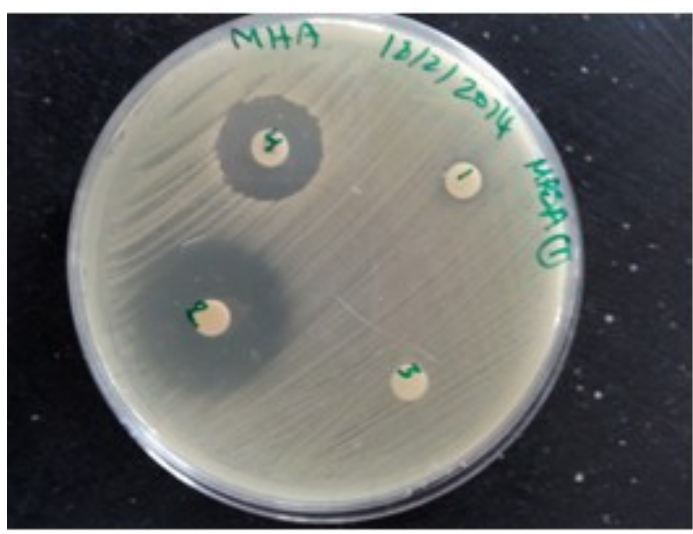

Figure 1: Diameters of inhibition zones (mm) of Thymus vulgaris essential oil against MRSA. (1. Water, 2. Thymus essential oil, 3. Water, 4. Vancomycin)

Thymus essential oil was found to have antimicrobial activity against all microorganisms tested except in Pseudomonas aeruginosa which is a known drug resistant bacterium. The same result also was found by Lambert [16]. As to the question: why Thymus essential oil was found to be active against MRSA but not against Pseudomonas aeruginosa, the answer may lie in its composition. Thymus essential oil contains thymol and carvacrol which are considered to be its most active ingredients against bacteria although the rest of the component may also be active [17-22]. Thymol and carvacrol are known to disrupt the cell membrane causing its structural and functional damage [16]. Pseudomonas aeruginosa has a highly impermeable outer membrane whereas MRSA does not. Impermeability of outer membrane makes it more difficult for thymol and carvacrol to enter inside the bacterial cell. In addition, while P. aeruginosa has a highly active efflux pump that can very quickly pump foreign compounds back out of the cell before they can cause any damage; MRSA does not [23].

\section{Conclusion}

This study paper showed that the essential oil of Thymus vulgaris was active against antibiotic resistant bacteria including MRSA so that essential oils may represent a cheap, safe and effective treatment option against antibiotic-resistant pathogens.

\section{References}

[1]. F. Bakkali, S. Averbeck, D. Averbeck, and M. Idaomar, Biological effects of essential oils-a review, Food Chem Toxicol, 46, 2008, 446-475.

[2]. L. Oyen, and N. Dung, Plant Resources of South-east Asia No 19 Essential -oil plants (Backhuys, Leiden, Netherlands; 1999).

[3]. F. Senatore, Influence of harvesting time on yield and composition of the essential oil of a Thyme (Thymus pulegioides L.) growing wild in Campania (Southern Italy), J Agric Food Chem, 44, 1996: 1327-1332.

[4]. E. Stahl-Biskup, and F. Saez, Thyme (Taylor and Francis, London, 2002).

[5]. B.A. Abu-Irmaileh, and F. U. Afifi, Herbal medicine in Jordan with special emphasis on commonly used herbs, J Ethnopharmacol, 89, 2003, 193-197.

[6]. M. E. Mulligan, Methicillin-resistant Staphylococcus aureus: a consensus review of microbiology, pathogenesis, and epidemiology with implications for prevention and management, Am. J. Med, 94, 1993, 313-328.

[7]. C. Theaker, S. Ormond-Walshe, B. Azadian, and N. Soni, MRSA in the critically ill, J Hosp Infect, 48, 2001, 98-102.

[8]. J. Lawless, Tea Tree Oil (United Kingdom, Thorsons; 1994).

[9]. S. Shapiro, A. Meier, and B. Guggenheim, The antimicrobial activity of essential oils and essential oil components towards oral bacteria, Oral Microbiol Immuno, 19, 1994, 202-8.

[10]. J. V. Larrondo, M. Agut, and M. A. Calvo-Torras, Antimicrobial activity of essences from labiates, Microbios, 82, 1995, 171-2.

[11]. M. Harkenthal, J. Reichling, H. K. Geiss, and R. Saller, Comparative study on the in vitro antibacterial activity of Australian tea tree oil, cajuput oil, niaouli oil, manuka oil, kanuka oil, and eucalyptus oil. Pharmazie, 4, 1995, 460-3. 
[12]. G. Sacchetti, S. Maietti, M. Muzzoli, M. Scaglianti, S. Manfredini, M. Radice, and R. Bruni, Comparative evaluation of 11 essential oils of different origin as functional antioxidants, antiradicals and antimicrobials in foods. Food Chem, 91, 2005, 621-632.

[13]. B. Imelouane, H. Amhamdi, J. P. Wathelet, M. Ankit, K. Khedid, and A. El Bachiri, Chemical Composition and Antimicrobial Activity of Essential Oil of Thyme (Thymus vulgaris) from Eastern Morocco, Int J Agric Biol; 11, 2009, $205-208$.

[14]. A. Grigore, I. Paraschiv, S. Colceru-Mihul, C. Bubueanu, E. Draghici, and M. Ichim, Chemical composition and antioxidant activity of Thymus vulgaris L, Romanian Biotechnological Letters, 15, 2010, 5436-5443.

[15]. A. De Lisi, L. Tedone, V. Montesano, G. Sarli, and D. Negro, Chemical characterisation of Thymus populations belonging from Southern Italy, Food Chem, 125, 2011, 1284-1286.

[16]. R. J. Lambert, P. N. Skandamis, P. J. Coote, and G. J. E. Nychas, A study of the minimum inhibitory concentration and mode of action of oregano essential oil, thymol and carvacrol, J Appl Microbiol, 91, 2001, 453-462.

[17]. Y. Massada, Analysis of essential oil by gas chromatography and mass spectrometry (John Wiley and Sons, New York, USA; 1976).

[18]. I. M. Helander, H. L. Alakom, K. Latva-Kala, T. Mattıla- Sandholm, I. Pol, E. J. Smd, L. G. M. Gorris , and A. Von Wright, Characterization of the action of selected essential oil components on Gram-negative bacteria, J Agric Food Chem, 46, 1998, 35903595.

[19]. S. Cosentino, C. I. Tuberoso, B. Pisano, M. Satta, V. Mascia, E. Arzedi, and F. Palmas, In vitro antimicrobial activity and chemical composition of sardinian Thymus essential oils, Lett. Appl Microbiol, 29, 1999, 130-135.

[20]. P. M. Davidson, and A. S. Naidu, Phyto-phenol, In A. S. Naidu (Ed.), Natural Food Antimicrobial Systems, (CRC Press, Boca Raton, Florida; 2000) 56-89.

[21]. M. Skocibusic, N. Bezic, and V. Dunkic, Phytochemical composition and antimicrobial activities of essential oils from Satureja subspicatais Growing in Croatia, Food Chem, 96, 2006, 20-28.

[22]. M. C. Rota, A. Herrera, R. M. Martinez, J. A. Sotomayor, and M. J. Jordan, Antimicrobial activity and chemical composition of Thymus vulgaris, Thymus zygis and Thymus hyemalis essential oils, Food Cont, 19, 2007, 681-687.

[23]. L. Pray, Antibiotic resistance, mutation rates and MRSA. Nature Education; 1(1), 2008, 30. 